\title{
Making social studies social: Engaging students through different forms of social perspective taking
}

\section{Citation}

Gehlbach, Hunter. 2011. Making social studies social: Engaging students through different forms of social perspective taking. Theory into Practice 50, no. 4: 300-310.

\section{Published Version}

doi:10.1080/00405841.2011.607394

\section{Permanent link}

http://nrs.harvard.edu/urn-3:HUL.InstRepos:5372034

\section{Terms of Use}

This article was downloaded from Harvard University's DASH repository, and is made available under the terms and conditions applicable to Other Posted Material, as set forth at http:// nrs.harvard.edu/urn-3:HUL.InstRepos:dash.current.terms-of-use\#LAA

\section{Share Your Story}

The Harvard community has made this article openly available. Please share how this access benefits you. Submit a story.

Accessibility 
Making social studies social:

Engaging students through different forms of social perspective taking

\author{
Hunter Gehlbach \\ Harvard Graduate School of Education \\ Submitted September 1, 2010 \\ Revision submitted October 1, 2010 \\ Second revision submitted February 9, 2011
}

Word count: 3879

Contact information

Hunter Gehlbach

hunter_gehlbach@gse.harvard.edu

W: (617) 496-7318

Fax: (617) 495-9268 


\begin{abstract}
People are intrinsically motivated to connect to others socially. One of the most important mechanisms in fostering social relationships is social perspective taking (SPT) - our capacity to discern the thoughts and feelings of others. Thus, students in social studies classrooms might be motivated to engage with their subject either through taking the perspectives of their peers in class (interpersonal SPT) or through taking the perspectives of the historical and cultural figures they are studying (academic SPT). This article first provides a theoretical overview of the contrasts and similarities between these two forms of SPT. Next, it describes three examples of how these two forms of SPT might be implemented in teaching social studies.
\end{abstract}

KEYWORDS: social perspective taking, social studies, relatedness, engagement, motivation 


\section{Making social studies social: \\ Engaging students through different forms of social perspective taking}

As a teacher, most of Ms. Smith's job related angst could be traced to two specific students. In and of themselves, they were typical $8^{\text {th }}$ grade social studies students - both enjoyable to teach as individuals. However, how to keep both engaged simultaneously seemed too vexing a riddle for even the most accomplished master teacher. This was the conundrum that kept her up at night.

The first student, Sammy, was as interested in social studies as Abraham Lincoln was in Scandinavian politics. He was not opposed to the subject matter in principle, but its relevance to him was vague - more pressing issues loomed larger on his horizon. Despite caring little about the historical figures confronting him in his textbook, Sammy maintained a passionate interest in his classroom neighbors. Consequently, Ms. Smith could engage him through collaborative projects - especially those in which students could compare their opinions on different issues. However, as soon as the pedagogical approach became less social, Sammy's engagement withered.

Samantha's engagement represented the mirror image of Sammy's. For reasons that eluded Ms. Smith, Samantha had no interest in her classmates. Samantha did not seem shy exactly, but speaking up in front of the whole class was her personal purgatory, small groupwork was little better, and working one-on-one with a partner was barely tolerable. In these social contexts, Samantha actively disengaged. By contrast, she relished learning different explanations for why people from varied cultures and historical periods behaved as they did and how their cultural beliefs developed. Samantha' engagement peaked while reading different points of view on the same topic (e.g., translations from Arab and Israeli newspapers covering each side of their conflict). These activities kept her reading long after the sound of the bell ended class.

Ms. Smith felt stuck. Engaging Sammy seemed necessarily to alienate Samantha and the reverse held just as true. Simultaneously engaging both seemed out of the question.

Ms. Smith's conundrum of simultaneously engaging students with disparate interests while teaching a single curriculum resonates with many teachers. For social 
studies teachers this motivational challenge is especially acute as students often identify this subject as one of the least motivating and least important (Gehlbach et al., 2008; Wolters \& Pintrich, 1998). Although a panacea that motivates all students all the time seems unlikely, this article explores the possibility that the interests of Sammy and Samantha are, at a fundamental level, the same. Specifically, they are both engaged by the act of taking the perspective of others - an act that many students will find motivating. Thus, activities that facilitate perspective taking might spark student engagement in social studies (or other content areas) across a broad range of students and settings. To explore this possibility, this article attempts to: (a) conceptualize two different forms of social perspective taking (SPT) and describe their essential, overlapping features at a theoretical level and (b) offer practical illustrations of how teachers might use this conceptualization to increase student motivation and engagement.

\section{A Theoretical Frame: \\ The Common Core of Two Distinct Forms of Social Perspective Taking}

So what exactly is SPT? How can two students who are engaged by ostensibly opposite activities actually be motivated by the same basic phenomenon? SPT is a process through which a "perceiver" attempts to discern the thoughts, feelings, motivations, and/or point of view of one or more "targets." To do this effectively the perceiver often needs to understand how a particular situation appears to a target. For example, Sammy might wish to learn which current events most interest Ms. Smith and how he might lure her into discussing one of these events instead of starting class. Meanwhile, as Samantha reads Martin Luther King's Letter from Birmingham Jail, she might wish to understand what King felt as he wrote to the whole world from the isolation of a small jail cell. It should be noted that SPT is an aptitude consisting of ability and motivation (Gehlbach, 2004). In other words, Sammy and Samantha might make more or less accurate inferences about Ms. Smith and MLK; but they will also vary in their motivation to take the perspective of these two targets.

Even with this definition of SPT, the assertion that SPT could motivate both students still seems tough to advance - if Sammy and Samantha engage in social studies through this same fundamental SPT process, why does one engage in class at the exact 
moment when the other disengages? It turns out that SPT takes many different forms perhaps because it is essential across so many contexts. Understanding others is a core human process - so much so that humans have developed specialized neural systems to facilitate our understanding of others (Gallese \& Goldman, 1998). Yet, this core process happens in many different ways depending on the characteristics of the perceiver, the target, and the surrounding context. For example, individuals are motivated to initially engage in (or not engage in) SPT for a host of different reasons (Gehlbach, Brinkworth, \& Wang, in press). Similarly, individuals rely on different strategies and sources of evidence in their SPT attempts (Gehlbach \& Brinkworth, in press). So what exactly are the distinctions and core similarities between the SPT processes of Sammy and Samantha?

\section{Differences Between Interpersonal and Academic Social Perspective Taking}

More closely examining the ilk of SPT that Sammy and Samantha engage in illuminates distinct, yet overlapping, facets of SPT. For example, Sammy engages most when taking the perspective of his peers. He is interested in better understanding them as a means of connecting with them socially. Thus, he frequently tries to take their perspective during interactions in the present moment - he reads their facial expressions, makes inferences from their tone of voice, studies their gestures or posture, and so on. Furthermore, he can take an active role in these interactions. Sammy can ask questions to clarify meaning, he can monitor responses to his comments and behaviors, and he can even disclose his own opinion to encourage his peers to reciprocate by revealing more about their point of view.

By contrast, Samantha engages most when she is learning to reconcile divergent points of view that she reads about historical figures. In this form of perspective taking, she generally cannot interact with the SPT targets because they are historical figures or authors who have written on historical topics (i.e., they are dead or otherwise inaccessible). To better understand the figures of interest, she must reflect on them, their circumstances, their personal histories, and how they might have perceived the environments in which they found themselves. More challenging still, she has relatively few sources of information from which she can draw inferences about these historical 
figures. She lacks a visual sense of who they are or how they behaved; she has no facial expressions, tone of voice, or gestures to rely upon. Instead, she will likely need to consult written sources.

There is little doubt that these are two very different forms of SPT. Sammy is predominantly interested in what we might call "interpersonal" SPT; he primarily wants to better understand the others who inhabit his social world. Meanwhile, Samantha engages in "academic" SPT. She tries to better understand those who constitute the objects of study in her social studies class ${ }^{1}$. The characteristics of each form of SPT described above and listed in Table 1 are not discrete. While engaging in interpersonal and academic SPT, Sammy and Samantha will often face constraints or affordances that typify the other form of SPT. For example, Sammy may engage in SPT through a less active, more observational role. As a third party to an interaction between others, he may simply watch and listen to his peers, without asking questions or testing their reactions to his actions. Samantha may find herself attempting to take the perspective of more current historical figures for whom she can view video footage that allows for drawing inferences from facial expressions, tone of voice, gestures, and so on. The point is that these two different forms of SPT typically differ on several key characteristics.

$* * * * * * * * * * * * * * * * * * * * * * *$

Insert Table 1 about here

$* * * * * * * * * * * * * * * * * * * * * * *$

\section{Similarities across Interpersonal and Academic Social Perspective Taking}

At the same time, these two forms of SPT have important, fundamental similarities. As the definition of SPT indicates, both involve discerning the cognitions and emotions of targets as a means to better understanding their values, motivations, and behaviors. Each form encompasses elements of SPT ability (a perceiver will read a peer or a historical figure with some level of accuracy) and SPT motivation (perceivers will inevitably differ in the frequency with which they attempt to read peers or historical

\footnotetext{
${ }^{1}$ These preferences might be reversed in other classes i.e., in a different context, Sammy might be more invested in the subject matter and/or Samantha might be more interested in connecting with her peers.
} 
figures). Perhaps most importantly from a pedagogical point of view, both forms signal student engagement.

However, the similarities extend to the process of SPT itself. In both forms, a combination of a perceiver's general disposition to engage in SPT and specific situational triggers combine to motivate perceivers to initiate the SPT process (Gehlbach, et al., in press). Next, perceivers select an SPT strategy and begin to amass information about the target in question. Complimentary to this data collection process, perceivers begin forming theories as to the thoughts, feelings, and motivations of the targeted individual (Gehlbach \& Brinkworth, in press). As these theories coalesce, the perceivers may need to seek new information. Over the course of the process, perceivers' confidence in their assessment will wax and wane; correspondingly, their motivation may increase or decrease. Regardless of the form of SPT in question, these aspects - initial motivation to engage in SPT, strategy selection, gathering information from sources of evidence, and hypothesis generation - are core to the SPT process and continuously impact one another.

Beyond the similarities in the SPT process, both interpersonal and academic SPT are susceptible to an array of biases that can degrade a perceiver's ability to make accurate inferences. Though perceivers are generally motivated to perceive those in their social world accurately, this motivation can be derailed by the motivation to think efficiently and/or by the motivation to preserve one's sense of self (Gehlbach \& Brinkworth, 2008). In other words, perceivers strive to understand others as they truly are, but occasionally they lack the time or cognitive energy to accurately discern others. Consequently, sometimes perceivers take shortcuts in their thinking. For example, Samantha might conclude that Neville Chamberlain was a colossal wimp for appeasing Hitler without taking the time to appreciate the severe circumstances Britain faced after World War I. By over-attributing Chamberlain's decision to a trait like "wimpiness" rather than appreciating his situational constraints, Samantha would commit the fundamental attribution error (Ross, Amabile, \& Steinmetz, 1977). These types of mental shortcuts save time and cognitive effort (and surprisingly often, they lead perceivers to reasonably accurate conclusions). However, they can also result in costly mistakes. 


\section{The Role of Social Perspective Taking in Social Relatedness}

Arguably, the most important commonality between these forms of SPT is that both provide a means through which individuals can relate to others. It is this sense of social connectedness that allows teachers to engage students like Sammy and Samantha simultaneously. Through both forms of SPT, perceivers better understand who is friendly (or fearsome), who might hold shared values, and whose behaviors might provide social support. In short, SPT is the capacity that allows perceivers to screen others as potential candidates for social relationships. Beyond insights into who might become a good source of relatedness, SPT also provides crucial information about how to foster relatedness. When a joking comment about the cushy life of the classroom teacher is met with a pained fake smile, one might infer that further jokes on that topic will endanger, rather than enhance, the social bond.

Students' sense of relatedness, in turn, is likely to spark engagement. The benefits of social relatedness are multiple and profound. Martin and Dowson (2009) note that social bonds help buffer against stress. Social support, in many different forms, has well-established benefits for people's mental and physical health (Taylor et al., 2004). Interestingly, there appear to be benefits to simply perceiving that one has social support (i.e., not actually using one's support network, but merely believing that it is there). Given these benefits, it is unsurprising that scholars assert that we are fundamentally motivated to relate to others (Ryan \& Deci, 2000). To the extent that teachers provide opportunities for their students to develop social bonds, their students will be intrinsically motivated to engage in those activities.

In summary, SPT is, perhaps, the key mechanism in understanding others and developing relationships with them. Because social relationships are so important to people, they are intrinsically motivated to engage in activities where they can pursue such relationships.

\section{Practice: Promoting student engagement through social perspective taking}

Given the potential for students with interests as diverse as Sammy and Samantha to be intrinsically motivated by this same underlying process, it seems reasonable for teachers to experiment with classroom exercises that incorporate SPT. Three broad 
approaches seem especially promising for social studies teachers: collaborative SPT on a common content-related target, humanizing history, and cultivating/exploring students' diverse perspectives on key course topics.

\section{Collaborative Social Perspective Taking}

In social settings, individuals sometimes engage in SPT by reflecting on a target of interest with the aid of others (Gehlbach \& Brinkworth, in press). Social studies teachers can encourage this SPT strategy by posing questions to pairs or small groups of students such as: "Why did this particular historical figure act as she did?" or "What circumstances led to a certain culture adopting a particular belief or point of view?" Having students adopt this particular SPT strategy provides several advantages. Perceivers should generally develop more hypotheses to explain a historical figure's behavior with two (or more) minds versus one. Second, to the extent that one person succumbs to a particular bias with respect to a given SPT target, others may be able to provide a more "objective" perspective. Third, as various hypotheses and explanations of a target are averaged and/or synthesized, the resulting explanations are more likely to be accurate (Herzog \& Hertwig, 2009).

Perhaps most important, the social nature of the collaboration and the multiple perspectives generated about the SPT target of interest provide multiple entry points for motivating students to engage in the content. In other words, Sammy can be excited about this exercise because he has learns about his peers' thoughts and how they perceive others. Although Samantha may remain chagrinned about interacting with other students, she will be rewarded by learning new explanations and possibilities as to why certain historical figures believed certain actions to be sensible. Younger students may need to be introduced to collaborative SPT in a more gradual and structured way. For example, elementary school students could write down their own perspective first, share it with a peer, jointly revise their perspective, then share that synthesized perspective with another pair, and create a final perspective. Teachers might help students see how their perspectives evolve over time by having students write each perspective on a separate sheet of paper and then post them in similar fashion to mini tournament draw-sheets. 


\section{Humanizing History}

Social studies curricula often center on history. Although intrinsically fascinating to many, history has, at times, been reduced to an inane game of coverage in which teachers and texts generate expansive lists of facts, events, and corresponding dates for students to memorize and regurgitate (VanSledright \& Limon, 2006). This approach to historical study essentially exorcises the people from the story. Winston Churchill reduces to "1940, British leader, politician, 1945, Second Boer War, prime minister," and so on. He is no longer a captivating individual whose early speech impediment somehow did not inhibit outrageous remarks such as his famed retort to an observer of his drunkenness... yes, indeed he was drunk, but in the morning, he would be sober, while she would still be ugly. These details make historical figures human for students of history. Although the historical relevance of this one particular interchange may be minimal, the study of human history is, at its foundation, the understanding the actions and reactions of people. If students are to understand the actions of historical figures, they must understand the figures themselves. Anecdotes like these paint a vivid picture about the kind of person that Churchill was.

By moving the people of history into the foreground, teachers can capitalize on students' intrinsic need for social relatedness and can use SPT as a means towards that end. In practical terms, Sammy decides whether someone like Churchill is the type of person he would like to get to know while Samantha learns the origins and bases of his views and others' views of him. It is a well-known best practice for teachers to first ascertain where students are in their knowledge of a certain topic (Bransford, Brown, \& Cocking, 1999). But why ask students to write down everything they know about Churchill when students could describe what they would ask Churchill if they could have tea with him? Rather than writing a report on why Churchill opposed Gandhi, ask students which facets of Churchill's background would have had to change for him to support the movement for Indian Independence. For younger students, more straightforward tasks like discussing whether and why they would want Churchill as a substitute teacher for a month may be more developmentally appropriate. These activities compel students to understand historical figures as people in meaningful ways, not just another abstract category of proper nouns to be committed to memory until 
Friday's test. Once students have a sense of the "person behind the historical figure," they are much more likely to remain engaged when studying the events that comprise the historical figure's life.

\section{Cultivating Students' Perspectives}

The notion of a classroom as a community of learners has been around for years (Brown \& Campione, 1994). Yet, it seems all too rare that students in social studies classrooms view their peers as valuable sources of wisdom. Although a teacher can comprehensively review all the major perspectives on whether the coalition forces were justified in invading Iraq and Afghanistan after the September $11^{\text {th }}$ attacks, this process fundamentally differs from an approach in which students are allowed to hear the respective perspectives of each another on that same question. Though the former approach offers efficiency, the latter approach offers distinct advantages. First, teachers will not always have a monopoly on all the points of view of a controversial topic. Thus, opening the class up to student opinions will likely broaden the range of perspectives to which students are exposed. This broader array of views should bolster student engagement - students are now more likely to resonate with at least one or two of the views presented. Furthermore, a student who does not identify with a particular perspective when it is framed with a teacher's more formal language, may resonate with the exact same idea when a peer describes it. Second, hearing the perspective of others allows students to better understand their classmates and help them evaluate the extent of their mutual connectedness on issues. In other words, cultivating students' perspectives helps them understand the controversial issue in question from different vantage points, but also helps them better understand their peers. Finally, this process allows teachers to assess students' prior knowledge, beliefs, and misconceptions about a topic. With this extra information about students, teachers can better determine optimal pedagogical approaches.

As before, this approach allows for multiple entry points through which students can engage in an activity. So although Sammy's primary interest might be in learning about his peers through hearing their points of view, he still will acquire a set of perspectives and arguments on both sides of this question as collateral learning. 
Conversely, Samantha may be predominantly interested in the controversial issue itself, but as an added benefit she will sense which classmates share similar views to her. This may offer her an avenue through which she can connect to other students. Teachers of younger students may wish to scaffold these types of activities so as to reduce cognitive load. For instance, students could first interview 1-2 others on their perspective to hear the content of just one divergent point of view at a time before having a whole class discussion on all the different points of view. As needed, teachers may wish to focus first on the variety and diversity of the student perspectives and then, in a second pass over the material, focus on the content of those perspectives.

A note of caution warrants mention. To the extent that teachers bring up controversial issues in class that are personal to students in some way (e.g., some students may have relatives who have fought in Iraq or Afghanistan), they will need to take extra care in establishing classroom norms. Specifically, students need to develop the habit of disagreeing with positions, not people, and appreciating points of view that diverge from their own. Teachers can set the tone for this environment by expressing extra gratitude and enthusiasm for hearing well-reasoned points of view with which they personally disagree. To blur the lines between those who are on different sides of an issue, teachers can also help students identify elements of difference between ostensibly similar positions and find common ground at the core of opposing points of view.

\section{Conclusion}

Perhaps most important for social studies teachers attempting to bolster student engagement is to illustrate to students how toggling back and forth between "interpersonal" and "academic" can reinforce one another. As students become more adept at the SPT process, teachers can guide them to transfer their abilities in one domain to the other (e.g., through asking students to engage in metacognitive reflection). In an email correspondence, Jere Brophy introduced me to the idea of what he called "catch" versus "hold" factors (see Brophy, 2009, for a more complete explanation). Although he was referencing "big ideas," teachers might apply these "catch" and "hold" concepts to the present context. Specifically, teachers may be able to capture and hold some students' interests through interpersonal SPT and other students' interests through 
academic SPT; still other students might be captured by one and held by the other. Each of the three teaching approaches in the previous section should facilitate students' learning each form of SPT through exactly this type of back and forth in which they can catch students' interest from one form of SPT, extract meaningful lessons, and then apply those lessons to the other.

In today's rapidly globalizing world, social studies teachers must facilitate their students' understanding and appreciation of the ideas, values, beliefs, and motivations of people from different cultures and/or historical time-periods. To a much greater degree than ever before students need to blend their abilities to engage in interpersonal SPT (e.g., trying to discern why a peer is upset) with academic SPT (e.g., knowing the ways in which that peer's cultural background may contribute to his or her emotional state). Without question, today's students will interact with more and more people who come from different backgrounds. How well they can understand these individuals depends, at least in part, on how well teachers can help foster their SPT skills and motivation. 


\section{References}

Bransford, J., Brown, A. L., \& Cocking, R. R. (1999). How people learn: Brain, mind, experience, and school. Washington, D.C.: National Academy Press.

Brophy, J. (2009). Connecting with the big picture. Educational Psychologist, 44(2), 147157.

Brown, A. L., \& Campione, J. C. (1994). Guided discovery in a community of learners. In K. McGilly (Ed.), Classroom lessons: Integrating cognitive theory and classroom practice. (pp. 229-272). Cambridge: The MIT Press.

Gallese, V., \& Goldman, A. (1998). Mirror neurons and the simulation theory of mindreading. Trends in cognitive sciences, 2(1), 493-501.

Gehlbach, H. (2004). A new perspective on perspective taking: A multidimensional approach to conceptualizing an aptitude. Educational Psychology Review, 16(3), 207-234. doi: 10.1023/b:edpr.0000034021.12899.11

Gehlbach, H., \& Brinkworth, M. E. (2008). Motivated thinkers and the mistakes they make: The goals underlying social cognitions and their consequences for achievement. In M. L. Maehr, S. Karabenick \& T. Urdan (Eds.), Advances in motivation and achievement: Social psychological perspectives. (Vol. 15, pp. 119-144). Bingley, UK: Emerald.

Gehlbach, H., \& Brinkworth, M. E. (in press). The social perspective taking process: Strategies and sources of evidence in taking another's perspective. Teachers College Record.

Gehlbach, H., Brinkworth, M. E., \& Wang, M.-T. (in press). The social perspective taking process: What motivates individuals to take another's perspective? Teachers College Record.

Gehlbach, H., Brown, S. W., Ioannou, A., Boyer, M. A., Hudson, N., Niv-Solomon, A., et al. (2008). Increasing interest in social studies: Social perspective taking and self-efficacy in stimulating simulations. Contemporary Educational Psychology, 33(4), 894-914. doi: 10.1016/j.cedpsych.2007.11.002

Herzog, S. M., \& Hertwig, R. (2009). The wisdom of many in one mind: Improving individual judgments with dialectical bootstrapping. Psychological Science, 20(2), 231-237.

Martin, A. J., \& Dowson, M. (2009). Interpersonal relationships, motivation, engagement, and achievement: Yields for theory, current issues, and educational practice. Review of Educational Research, 79(1), 327-365.

Ross, L., Amabile, T. M., \& Steinmetz, J. L. (1977). Social roles, social control, and biases in social-perception processes. Journal of Personality and Social Psychology, 35(7), 485-494.

Ryan, R. M., \& Deci, E. L. (2000). Self-determination theory and the facilitation of intrinsic motivation, social development, and well-being. American Psychologist, 55(1), 68-78.

Taylor, S. E., Sherman, D. K., Kim, H. S., Jarcho, J., Takagi, K., \& Dunagan, M. S. (2004). Culture and social support: Who seeks it and why? Journal of Personality and Social Psychology, 87(3), 354-362. doi: 10.1037/0022-3514.87.3.354

VanSledright, B., \& Limon, M. (2006). Learning and teaching social studies: A review of cognitive research in history and geography. In P. A. Alexander \& P. H. Winne 
(Eds.), Handbook of educational psychology (2nd ed., pp. 545-570). Mahwah, N.J.: Lawrence Erlbaum.

Wolters, C. A., \& Pintrich, P. R. (1998). Contextual differences in student motivation and self-regulated learning in mathematics, English, and social studies classrooms. Instructional Science, 26(1-2), 27-47. 
Table 1: Comparison of social perspective taking forms

Interpersonal

Academic

Key differences

The target is often present in the situation and multiple information channels may be used (e.g., tone of voice, facial expressions, and gestures).

"Active" SPT is often possible whereby the perceiver can interact with the target (e.g., asking questions).
The target is usually absent from the situation, thereby limiting the number of information channels a perceiver can use.

"Reflective" SPT is usually required in which the perceiver reflects on previously accumulated information about the target.

Key commonalities

In both processes a perceiver discerns the thoughts, feelings, motivations, etc. of one or more targets.

In both cases, SPT aptitude consists of the motivation and ability to accurately read others.

During each SPT process a perceiver's motivation, SPT strategies, the sources of evidence they rely on, and the explanatory theories they begin to develop will impact one another continuously.

Both forms of SPT are susceptible to biases that diminish the likelihood of SPT accuracy.

Both forms of SPT constitute a means of forming a sense of social connectedness to others.

Both forms of SPT signal engagement. 


\section{Additional Resources for Classroom Use}

Facing History and Ourselves: http://www.facinghistory.org/

This website will connect educators to a host of resources, lesson plans, and teaching strategies designed to connect students to historical figures and help them understand the context and constraints those figures faced. Although Facing History is not explicitly about social perspective taking, that theme is deeply rooted throughout many of their activities and workshops.

Gehlbach, H., \& Brinkworth, M. E. (2008). Motivated thinkers and the mistakes they make: The goals underlying social cognitions and their consequences for achievement. In M. L. Maehr, S. Karabenick \& T. Urdan (Eds.), Advances in motivation and achievement: Social psychological perspectives. (Vol. 15, pp. 119-144). Bingley, UK: Emerald.

This chapter describes the basic mistakes that people make as they try to accurately perceive others. It provides a theory for why people misperceive and misunderstand one another as well as the classroom implications of such misperceptions (including the consequences for teacher-student relationships). The chapter concludes with a discussion of how social perspective taking can mitigate these biases.

See also the Usable Knowledge link on social perspective taking: http://www.uknow.gse.harvard.edu/teaching/TC104-607.html

Johnson, D. W., \& Johnson, R. T. (2009). Energizing learning: The instructional power of conflict. Educational Researcher, 38(1), 37-51.

This article centers on "constructive controversy" - a classroom activity in which students engage in debates and are forced to take multiple points of view in those debates. Although much of this article focuses on the theory and research support for "constructive controversy," pages 40-41 provide step-by-step instructions for how to organize the activity. The research support for the effectiveness of this approach for student learning and engagement is tremendously impressive.

This article may be accessed via http://edr.sagepub.com/content/38/1/37.full 